\title{
19-Hydroxybufalin inhibits non-small cell lung cancer cell proliferation and promotes cell apoptosis via the $\mathrm{Wnt} / \beta$-catenin pathway
}

Wei Yu ${ }^{1,2}$, Xiao Zhang ${ }^{2}$, Wei Zhang ${ }^{2}$, Minggang Xiong ${ }^{2}$, Yuhan Lin² ${ }^{2}$ Ming Chang ${ }^{2}$ Lin Xu ${ }^{1}$, Yi Lu Lu $^{2,3^{*}}$, Yun Liu ${ }^{1 *}$ and Jian Zhang ${ }^{2,3^{*}}$

\begin{abstract}
Background: Bufadienolides derived from the skin of toads are often regarded as the main active components with antitumor effects. 19-Hydroxybufalin (19-HB) is a monomer of bufadienolides; however, its effects and underlying molecular mechanisms on tumor growth remain to be ascertained. In this report, we focused on the antitumor effects of 19-HB on non-small cell lung cancer to provide a scientific basis for its further development and utilization.

Methods: The antitumor effects of 19-HB on the human NSCLC cell lines NCl-H1299 and NCl-H838 were examined in vitro. The cells were treated with different concentrations of 19-HB, and the inhibition of cell growth was measured by CCK-8 and colony formation assays. Furthermore, cell apoptosis was analyzed by flow cytometry, TUNEL staining, JC-1 staining, and western blotting. The effects on migration and invasion were evaluated by wound-healing assay, transwell assay, and western blotting. Finally, the antitumor effects of 19-HB were evaluated in vivo using a xenograft mouse model.

Results: $19-\mathrm{HB}$-treated NSCLC cells showed inhibited cell viability and increased apoptosis. The expression levels of cleaved caspase-3, cleaved-PARP, and Bax/Bcl-2 were upregulated, while the mitochondrial membrane potential decreased. In contrast, migration, invasion, as well as the expression of MMP2, MMP7, MMP9, the epithelial-mesenchymal transition-related proteins N-cadherin and Vimentin, and the transcription factors Snail and Slug were inhibited. Furthermore, the expression levels of the key molecules in the Wnt/ß-catenin signaling pathway (CyclinD1, c-Myc, and $\beta$-catenin) were decreased. In vivo, the growth of xenograft tumors in nude mice was also significantly inhibited by $19-\mathrm{HB}$, and there were no significant changes in biochemical indicators of hepatic and renal function.

Conclusions: $19-\mathrm{HB}$ inhibited the proliferation, migration, and invasion, and promoted the apoptosis of NSCLC cells via the Wnt/ß-catenin pathway. In addition, 19-HB inhibited the growth of xenograft tumors in nude mice with little toxicity to the liver and kidney. Thus, 19-HB may be a potential antitumor agent for treating NSCLC.
\end{abstract}

Keywords: 19-Hydroxybufalin, Apoptosis, NSCLC, Migration and invasion

*Correspondence: luy3@sustech.edu.cn; liuyunzmu@126.com; zhangjian@sustech.edu.cn

${ }^{1}$ Guizhou Provincial College-Based Key Lab for Tumor Prevention and Treatment With Distinctive Medicines, Zunyi Medical University, Zunyi 563000, China

${ }^{2}$ School of Medicine, Southern University of Science and Technology, Shenzhen 518055, Guangdong, China

Full list of author information is available at the end of the article

\section{Background}

Lung cancer ranks as the second most common cancer worldwide [1]. Among all lung cancer patients, approximately $85 \%$ of them suffers in non-small cell lung cancer (NSCLC) based on histological characters [2]. In NSCLC, orchestrated signaling pathways cooperatively induce tumorigenesis, progression, and poor outcomes. original author(s) and the source, provide a link to the Creative Commons licence, and indicate if changes were made. The images or other third party material in this article are included in the article's Creative Commons licence, unless indicated otherwise in a credit line to the material. If material is not included in the article's Creative Commons licence and your intended use is not permitted by statutory regulation or exceeds the permitted use, you will need to obtain permission directly from the copyright holder. To view a copy of this licence, visit http://creativecommons.org/licenses/by/4.0/. The Creative Commons Public Domain Dedication waiver (http://creativecommons.org/publicdomain/zero/1.0/) applies to the data made available in this article, unless otherwise stated in a credit line to the data. 
Surgery, radiation therapy, chemotherapy, and targeted therapy are common current treatment options for NSCLC. Recently, immunotherapy has significantly improved the survival of patients with NSCLC or small cell lung cancer (SCLC) [3-5]. However, majority of lung cancer patients are not benefit from immunotherapy [6]. Currently, these options only provide limited effects on the overall survival, particularly in individuals with metastatic and chemoresistant phenotype. Therefore, searching for new molecular target and high-efficiency drugs is urgently needed [7-9].

Some natural products originating from Traditional Chinese Medicine (TCM) exhibit potential antitumor activities and have been used for the treatment of malignant tumors in China. An illustrative example is Bufo bufo gargarizans Cantor; it is an extremely precious medical material in China, well known as a TCM due to its pharmaceutical value [10]. Toad glandular secretions ("chansu" in Chinese), skin extractions, as well as the dried skin ("chanpi" in Chinese) have traditionally been used in cancer treatment [11]. These ingredients have been shown to exert antitumor effects, such as antiproliferative, proapoptotic, and antimetastatic effects; moreover, they regulate immunocompetence, reverse multidrug resistance, and attenuate cancer-derived pain [12-14]. The Huachansu (Cinobufacini) and Chansu injections have also been used in clinics with promising therapeutic effects in treating colorectal cancer, lung cancer, liver cancer, and other tumors as well [15-17]. Recent studies suggested that bufadienolides were important components of chansu and chanpi and might attribute to the bioactivity of them. 19-Hydroxybufalin (19-HB, Fig. 1a) [18], an ingredient of bufadienolides from the skin of toads, might participate in the antitumor activities. However, there is still no evidence of its effects and the potential biological mechanism for the application in lung cancer.

To explore the value of $19-\mathrm{HB}$ in treating lung cancer such as NSCLC, we investigated the effects and toxicity of 19-HB on NSCLC and explored the potential molecular mechanism. We found that 19-HB inhibited tumor progression through inhibiting the cell viability of NSCLC cells and promoted cell apoptosis. During the process, $\beta$-catenin, the key factor in $\mathrm{Wnt} / \beta$-catenin signaling pathway, as well as two classical dowmstream target genes, c-Myc and CyclinD1, were significantly decreased, suggesting that the antitumor effects of 19-HB may be mediated through suppressing Wnt/ $\beta$-catenin signaling pathway. In addition, biochemical indicators of hepatic and renal function showed that 19-HB also caused less hepatorenal toxicity. Our study provided a scientific basis for the clinical development and utilization of 19-HB, including further combinations with other antitumor therapies.

\section{Materials and methods Reagents}

19-HB was prepared from an aqueous extract of Chanpi and was prepared as a stock solution of $10 \mathrm{mM}$ in DMSO. Western blot antibodies targeting Bcl-2, Bax, cleavedcaspase3, total PARP, cleaved-PARP, MMP2, MMP7, MMP9, c-Myc, N-cadherin, $\beta$-catenin, Vimentin, Snail, Slug, and Cyclin D1 were purchased from Cell Signaling Technology (Beverly, MA, USA), and the antibody against $\alpha$-Tubulin was bought from Proteintech (Rosemont, IL, USA).

\section{Cell culture}

Human NCI-H1299, NCI-H838, A549, Huh7, HepG2 and MDA-MB-231 cell lines were obtained from the American Type Culture Collection (Manassas, VA, USA). The cells were cultured in RPMI 1640 or DMEM medium with $10 \%$ fetal bovine serum (FBS) and supplemented with $1 \%$ penicillin and streptomycin (Invitrogen, Carlsbad, CA, USA). The cells were maintained in a humidified chamber at $37{ }^{\circ} \mathrm{C}$ containing $5 \% \mathrm{CO}_{2}$. Cell morphology was observed under an inverted microscope (ECLIPSE Ti2, Nikon Corporation, Japan).

\section{Cell viability assay}

The cytotoxic effects of $19-\mathrm{HB}$ on the cancer cell lines NCI-H1299, NCI-H838, A549, Huh7, HepG2 and MDA-MB-231 were determined by Cell Counting Kit- 8 (CCK-8) assay (Yeasen, Shanghai, China). The cells were suspended in the medium described above that contained $10 \%$ fetal bovine serum (FBS) and antibiotics, then seeded in 96-well plates. Twenty-four hours later, different concentrations of $19-\mathrm{HB}$ were added to the plate and incubated for 24,48 , and $72 \mathrm{~h}$. At each indicated time point, $10 \mu \mathrm{L}$ CCK- 8 reagent was added to the each well of the plate and the optical density (OD) values were measured through the absorbance at $450 \mathrm{~nm}$ to calculate the cell viability.

\section{Colony formation assay}

NCI-H1299 and NCI-H838 cells were seeded in 6-well plates (500 cells/well). The cell culture medium was removed $24 \mathrm{~h}$ later; the cells were exposed to various concentrations of $19-\mathrm{HB}(0,30,60$, and $120 \mathrm{nM})$ for 14 days at suitable conditions. At indicated time point, the medium was removed, and the cells were washed with phosphate-buffered saline (PBS) twice. For fixation, the cells were incubated in $4 \%$ paraformaldehyde for $20 \mathrm{~min}$, then washed twice with PBS, and stained with $0.1 \%$ crystal violet for $20 \mathrm{~min}$. Photographs were taken 
a<smiles>C[C@]12CCC3C(CCC4C[C@@H](O)CC[C@]43CO)[C@@]1(O)CC[C@@H]2c1ccc(=O)oc1</smiles>

19-Hydroxybufalin (19-HB)

C

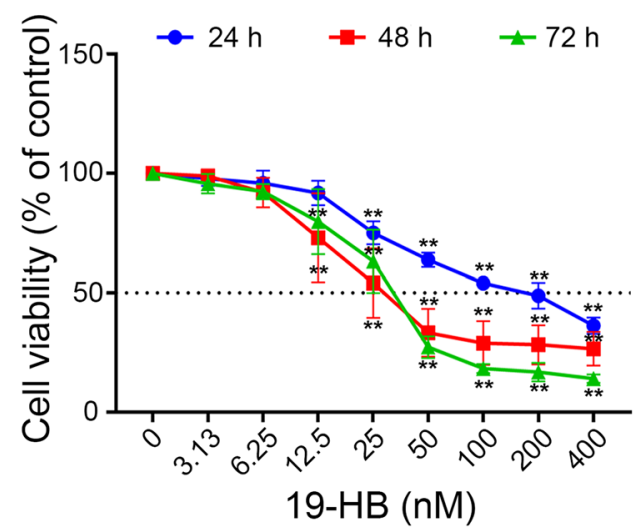

d

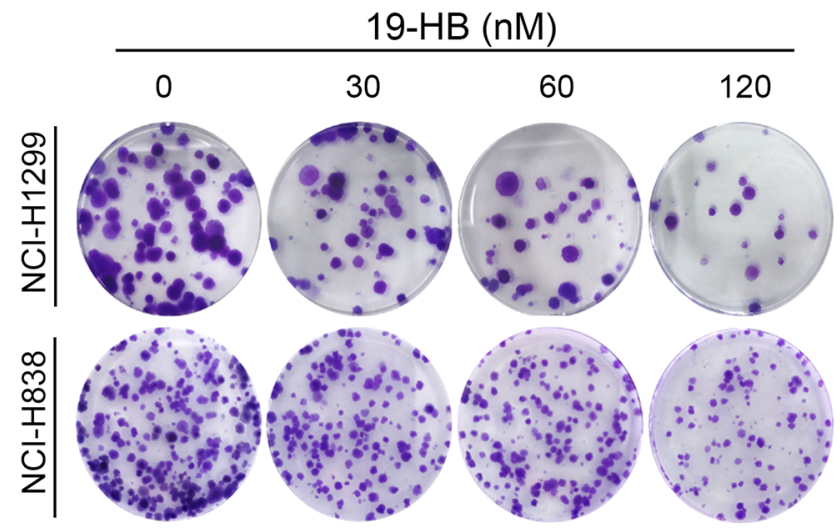

b

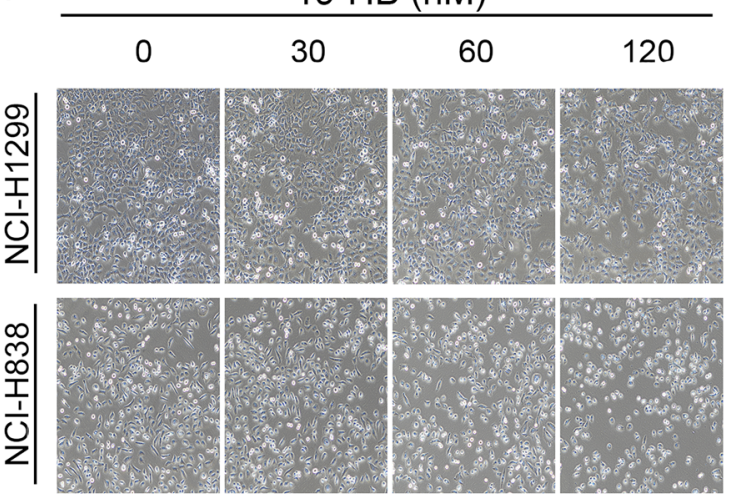

$\mathrm{NCl}-\mathrm{H} 838$

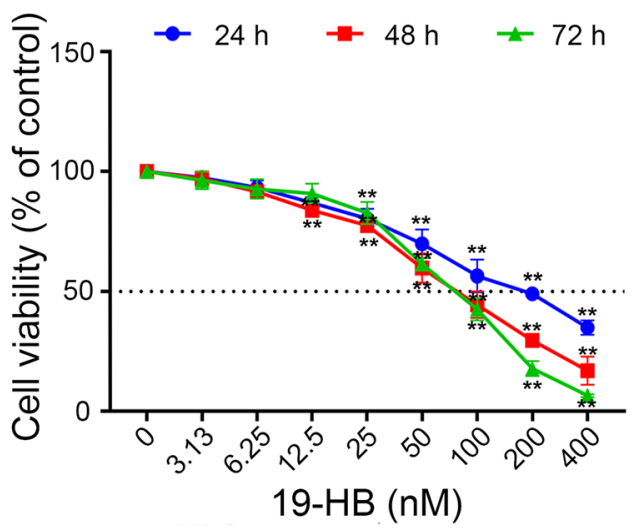

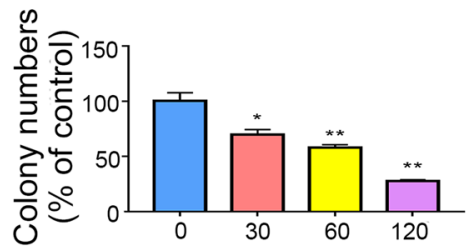

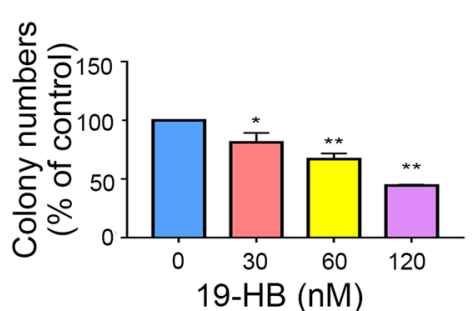

Fig. 1 19-HB inhibited proliferation and changed cell morphology in NSCLC cells. a Chemical structure of 19-HB. b Light scope showed cell morphology changes in NSCLC cells treated with 19-HB for $24 \mathrm{~h}$. c Cell viability was determined by a CCK-8 assay at 24, 48 , and $72 \mathrm{~h}$ after treatment. d Cell proliferation determined by colony formation assay and colony formation numbers were calculated after 14 days of culture in 24-h $19-$ HB-treated cell lines. The data are presented as the mean \pm SD of three parallel tests $\left({ }^{*} P<0.05\right.$ vs. control, ${ }^{* *} P<0.01$ vs. control) 
after washing with PBS to capture clear images, and colonies were counted.

\section{Flow cytometry analysis}

The apoptosis process induced by 19-HB was detected through a fluorescein isothiocyanate (FITC) Annexin V Apoptosis Detection Kit I (BD, Franklin Lakes, NJ, USA) in accordance with the instrument. In brief, approximately $10^{6}$ cells that had been treated with specific $19-\mathrm{HB}$ concentration were digested and incubated in 100 $\mu \mathrm{L}$ tubes with binding buffer containing $5 \mu \mathrm{L}$ of PI and $5 \mu \mathrm{L}$ FITC-annexin $\mathrm{V}$ in dark for $15 \mathrm{~min}$ at room temperature. Next, $400 \mu \mathrm{L}$ of $1 \mathrm{X}$ binding buffer was added to each tube, and the double staining signals were finally analyzed through a flow cytometer.

\section{TUNEL (TdT-mediated dUTP nick-end labeling) staining}

TUNEL assay (Beyotime, Shanghai, China) was used to examine the DNA fragmentation. The NSCLC cells were seeded onto 6-well plates and cultured for $24 \mathrm{~h}$; then, the cells were treated with increasing concentrations of $19-\mathrm{HB}(0,30,60$, and $120 \mathrm{nM})$ for totally $24 \mathrm{~h}$. The cells were fixed with $4 \%$ paraformaldehyde and incubated in accordance with the manufacturer's instructions before being observed under a fluorescence microscope.

\section{Mitochondrial membrane potential assay}

The NSCLC cells were exposed to $19-\mathrm{HB}(0,30,60$, and $120 \mathrm{nM}$ ) for $24 \mathrm{~h}$. According to the instructions, the cells were centrifuged, resuspended, and incubated in JC-1 staining solution. Finally, the JC-1 staining signal was analyzed by flow cytometry.

\section{Western blot analysis}

Whole-cell protein extracts were prepared with RIPA and protease inhibitors (99:1). Proteins were separated by sulfate-polyacrylamide gel electrophoresis and transferred to polyvinylidene difluoride membranes by electrotransfer. The membranes were blocked with 5\% BSA in Tris-buffered saline with Tween-20 and subsequently incubated with primary and secondary antibodies. The proteins on the membranes were visualized using the Chemiluminescent Reagents Kit. Chemiluminescent signals were detected with ChampChemi and quantified using ImageJ.

\section{Transwell assay}

NCI-H838 and NCI-H1299 cells $\left(2 \times 10^{4}\right.$ cells/100 $\left.\mu \mathrm{L}\right)$ were added to serum-free medium to the transwell upper chamber (Corning Star; Cambridge, MA, USA) with or without Matrigel. The indicated concentrations of $19-\mathrm{HB}$ or DMSO were added to the culture medium. Meanwhile, $750 \mu \mathrm{L}$ medium containing $10 \%$ or $20 \%$ FBS was added to the lower chamber as a chemoattractant to allow the cells to migrate or invade for $24 \mathrm{~h}$. The migrated or invasive cells on the chamber bottom were stained with $0.1 \%$ crystal violet after fixation with $4 \%$ paraformaldehyde for visualization. Five fields per chamber were randomly photographed for the quantification of migrated cells (ECLIPSE Ti2, Nikon Corporation, Japan). Invasive index was calculated as the ratio of the number of cells that had penetrated the Matrigel to the number of cells that had penetrated the uncoated Matrigel.

\section{Wound-healing assay}

NCI-H838 and NCI-H1299 cells $\left(2 \times 10^{4}\right.$ cells/well $)$ were seeded into 6-well plates with complete RPMI1640 medium and allowed to grow until the cell confluence reached $>95 \%$. And a sterile $200 \mu \mathrm{L}$ pipette tip was utilized to scrap a vertical wound. The cells were later treated with $19-\mathrm{HB}(0,30,60$, and $120 \mathrm{nM})$ in serumfree RPMI-1640 medium. The same field at each well was imaged with a microscope (ECLIPSE Ti2, Nikon Corporation, Japan) at three time points $(0,12$, and $24 \mathrm{~h})$ after the treatments. The images were processed and analyzed using Image J software, and the scratch areas of each observation point at different times were measured to calculate the cell migration rate.

\section{Reverse transcription quantitative real-time PCR}

TRIzol (Invitrogen) was used to extract total RNA from cells; the concentration and purity were determined using a NanoDrop spectrophotometer, and RNA was reverse-transcribed using Vazyme Reverse Transcription Reagents. Quantitative PCR was performed on a 7500 PCR machine (Applied Biosystems, Waltham, MA, USA) using SYBR Green PCR Master Mix. The relative gene expression level was calculated using the $2^{-\Delta \Delta \mathrm{Ct}}$ method normalized to $\beta$-actin. The primer sequences were as follows: forward primer sequence $5^{\prime}$-AGACAT ACATCTTTGCTGGAGACA- $3^{\prime}$ and reverse primer sequence $5^{\prime}$-CTTGAAGAAGTAGCTGTGACCG-3' for MMP2; forward primer sequence $5^{\prime}$-GGAGGAGATGCT CACTTCGAT- $3^{\prime}$ and reverse primer sequence $5^{\prime}$-AGG AATGTCCCATACCCAAAGA-3' for MMP7; forward primer sequence $5^{\prime}$-GGGACGCAGACATCGTCATC-3' and reverse primer sequence $5^{\prime}$-TCGTCATCGTCGAAA TGGGC- $3^{\prime}$ for MMP9; forward primer sequence $5^{\prime}$-CAT GTACGTTGCTATCCAGGC- $3^{\prime}$ and reverse primer sequence $5^{\prime}$-CTCCTTAATGTCACGCACGAT- $3^{\prime}$ for $\beta$-actin.

\section{Tumor xenografts model in nude mice}

The male Balb/c nude mice (4-6 weeks old) were kept in the Laboratory Animal Center at Southern University of Science and Technology. NCI-H1299 cells $\left(1 \times 10^{7}\right.$ cells in 
$0.1 \mathrm{~mL}$ of PBS mixed with Matrigel) were injected subcutaneously as indicated for nude mice. When the tumor volumes reached $50-80 \mathrm{~mm}^{3}$, the nude mice were randomly divided into a control group and a 19-HB group, with 5 mice in each group. The injection concentration of $19-\mathrm{HB}$ group was $1 \mathrm{mg} / \mathrm{kg}$; the control group received normal saline with the same amount of DMSO, and the intraperitoneal injection was given every other day and continued for 16 days. The tumor volume was calculated according to the following formula: volume $=$ width $^{2} \times$ length $/ 2$, and the tumor growth curve was presented. All the animals were sacrificed by dislocation after anesthesia. The tumor was dissected out from each mouse and the weight of each tumors were measured. The serum of mice was collected for biochemical analysis, and the tumors were collected for further analysis by immunohistochemistry and TUNEL staining.

\section{Immunohistochemistry and TUNEL staining}

Formalin-fixed, paraffin-embedded sections of xenograft tumors were subjected to immunohistochemistry following the routine protocols. The Ki67-positive cells in tumor tissues were counted, and the average number of positive cancer cells was determined from three separate areas in each section of five independent tumor samples. The apoptotic cells in the xenograft tumors from the nude mice were detected by TUNEL staining.

\section{Statistical analysis}

The independent and quantitative data among four groups were evaluated using one-way analysis of variance (ANOVA) followed by Dunn's post-hoc tests. P-values $<0.05$ were considered statistically significant. All statistical analyses were performed using the GraphPad Prism 7.0 software. Data were independently repeated for three times and presented as mean \pm standard deviation.

\section{Results \\ 19-HB inhibited NSCLC cells proliferation and suppressed colony formation}

To investigate the in vitro antitumor effects of $19-\mathrm{HB}$, we treated NSCLC cells with concentration gradient of 19-HB for 24,48 , and $72 \mathrm{~h}$ and measured their cell viability using CCK- 8 assay. The results showed that the exposure to $19-\mathrm{HB}$ resulted in a significant decline in cell viability in a dose-dependent manner in NCI-H1299 and NCI-H838 cell lines, compared with the untreated group $(P<0.01$, Fig. 1c and Additional file 1: Fig. S1). To further test the antitumor effects of 19-HB on other cancer cell types, liver cancer Huh7 and HepG2 cells, breast cancer MDA-MB-231 cells and lung cancer A549 cells were treated with 19-HB for indicated time. Similar results as H1299 and H838 were observed (Additional file 1: Fig. S2). Next, to assess the inhibitory effect on cell proliferation, which is essential in carcinogenesis, cell morphology and colony formation assay were adopted in a concentration gradient of 19-HB $(0,30,60,120 \mathrm{nM})$ after a $24-\mathrm{h}$ treatment. In the results showed under the microscope, the cell counts significantly declined in the 19-HB-treated group compared with the control group, along with varying degrees of deformation and contraction $(P<0.01$, Fig. $1 b)$. Consistent with these, clonogenicity ability was significantly suppressed upon the treatment of $19-\mathrm{HB}$ and led to a remarkable decrease in the colony formation ratio $(P<0.01$, Fig. $1 d)$. Taken together, the abovementioned results suggested that the treatment with 19-HB contributed to dose-dependent growth inhibition of NSCLC cells.

\section{9-HB promoted apoptosis of NSCLC cells}

Apoptosis is a cell suicide program, which functions to restrict the cell counts and eliminate malignant cells. The apoptosis induction in target cells is a critical approach in antitumor therapies [19]. As described above, distinct morphological changes in NSCLC cells may be due to 19-HB-induced cell contraction and apoptosis. Moreover, to evaluate the apoptosis induced by $19-\mathrm{HB}$, we compared the apoptosis rate of 19-HB-treated and untreated groups using multiple methods, consisting of Annexin V/PI double staining assay, TUNEL assay, JC-1 staining, and western blotting. After $24 \mathrm{~h}$ of treatment with $19-\mathrm{HB}$, flow cytometry results showed that the apoptotic proportions of four concentrations $(0,30,60$, $120 \mathrm{nM}$ ) were $3.63 \pm 0.12 \%, 3.07 \pm 0.16 \%, 6.99 \pm 0.37 \%$, and $11.59 \pm 0.60 \%$, respectively, in NCI-H1299 cells, and $3.06 \pm 0.65 \%, \quad 2.66 \pm 0.59 \%, \quad 6.84 \pm 0.99 \%$, and $9.56 \pm 1.35 \%$, respectively, in NCI-H838 cells (mean \pm SD, $P<0.01$, Fig. 2a). Furthermore, TUNEL assay showed that DNA fragmentation was upregulated in a dose-dependent manner at $24 \mathrm{~h}$, which also indicated the occurrence of cell apoptosis (Fig. 2b). Subsequently, we examined the

\footnotetext{
(See figure on next page.)

Fig. 2 19-HB induced apoptosis in NSCLC cells. NCl-H1299 and NCl-H838 cells were treated for $24 \mathrm{~h}$ with the indicated concentrations of $19-\mathrm{HB}$. a Percentage of apoptotic cells in 19-HB-treated cells versus DMSO-treated cells determined using flow cytometry analysis. b Quantitative apoptosis changes detected by TUNEL assay. TUNEL (red) was used to mark fragmented DNA, while DAPI (blue) was used to label the cell nuclei. c Western blotting using cell extract to detect the expression of cleaved caspase-3, cleaved PARP, and Bax/Bcl-2. Tubulin was used as the loading control, and the quantitative data of the protein levels are shown. $\mathbf{d}$ The changes in mitochondrial membrane potential measured by a JC-1 mitochondrial membrane potential assay kit, and the mitochondrial membrane potential was quantitatively analyzed ( ${ }^{*} P<0.05$ vs. control, ${ }^{* *} P<0.01$ vs. control)
} 
a 19-HB (nM)
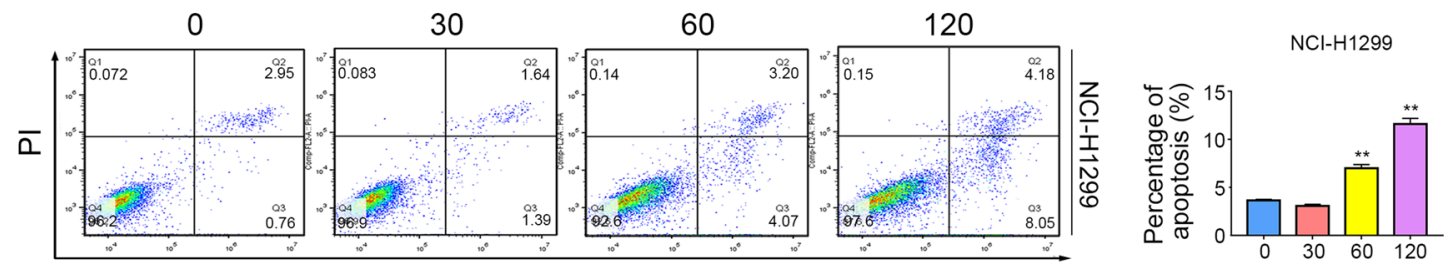

$\bar{\Omega}$
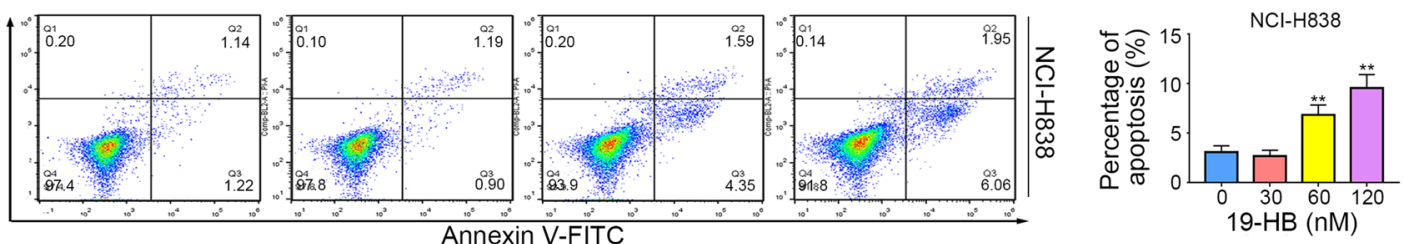

b

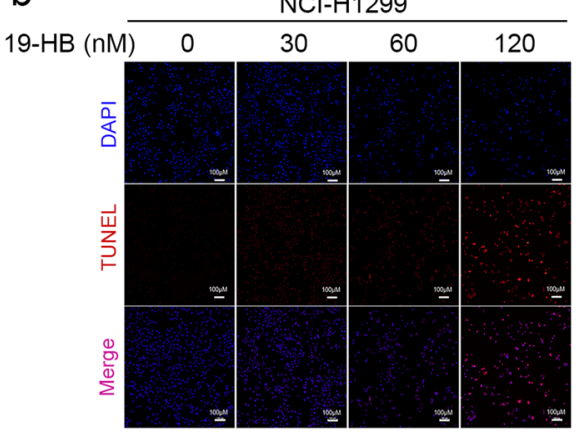

$\mathrm{NCl}-\mathrm{H} 838$

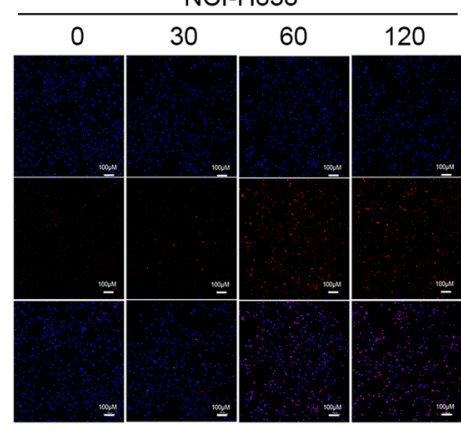

NCl-H1299

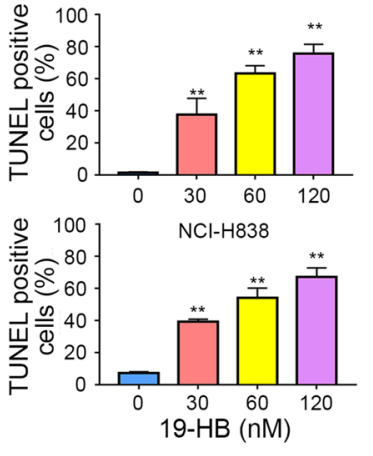

C
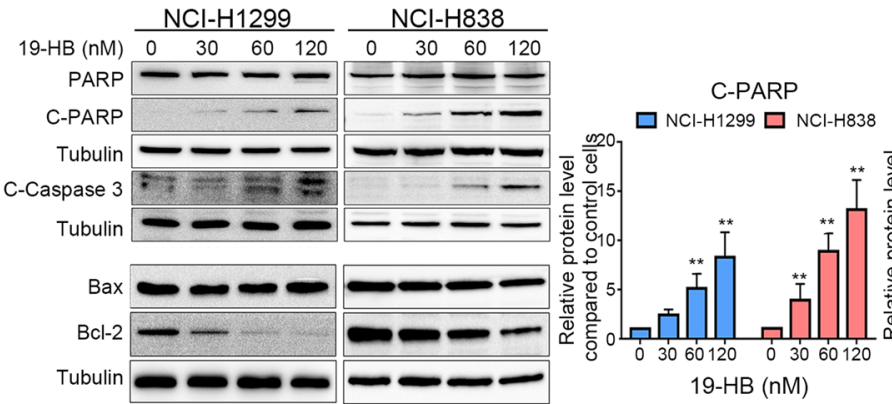

C-Caspase 3

$\mathrm{Bax} / \mathrm{Bcl}-2$

d 19-HB (nM)

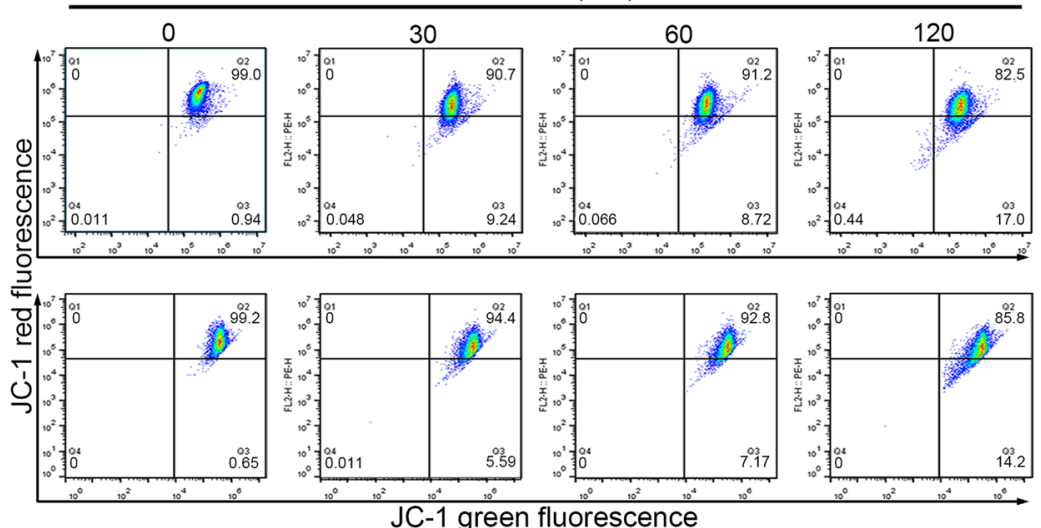

JC-1 green fluorescence

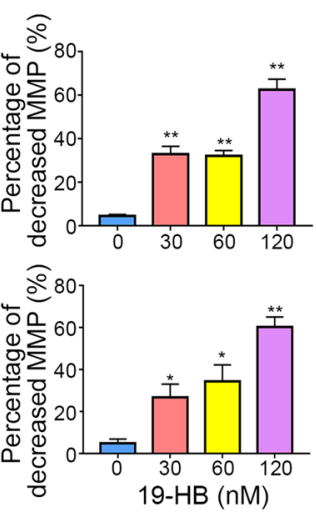

Fig. 2 (See legend on previous page.) 
levels of key proapoptotic genes (PARP and caspase-3) and mitochondrial apoptosis-related proteins $(\mathrm{Bax} / \mathrm{Bcl}-2)$ in both NCI-H1299 and NCI-H838 cells by western blotting analysis. Interestingly, 19-HB markedly upregulated the expression of cleaved caspase-3, cleaved-PARP and the ratio of the $\mathrm{Bax} / \mathrm{Bcl}-2$ levels, compared with the control group $(P<0.01$ vs. control, Fig. $2 \mathrm{c})$. The necroptoticrelated proteins, such as RIP, RIP3, and MLKL showed no significant changes in both cell lines (Additional file 1: Fig. S3). In conclusion, these results suggested that 19-HB reduced the proliferation of NSCLC cells through induction of apoptosis in vitro. We further inspected the mitochondrial membrane potential using JC-1 staining. Compared with the control group with $99.0 \%$ red fluorescence, the percentage gradually decreased to $90.7 \%$, $91.2 \%$, and $82.5 \%$ in the cells treated with the rising concentrations of $19-\mathrm{HB}(P<0.01$ in NCI-H1299, $P<0.05$ in NCI-H838); the ratio of green to red fluorescence increased as well (Fig. 2d). The above results indicated that 19-HB activated the mitochondrial apoptosis pathway in NSCLC cells.

\section{9-HB inhibited migration and invasion of NSCLC cells}

$19-\mathrm{HB}$ repressed the mobility of NCI-H838 and NCIH1299 cells as demonstrated in wound healing assay and transwell assay. Wound healing assay showed lower mobility of NSCLC cells compared with the untreated group $(P<0.01)$, and this effect positively correlated with the concentration of 19-HB (Fig. 3a). Moreover, migration and invasion abilities were also suppressed distinctly as shown in the transwell assay $(P<0.01$, Fig. 3b, c). Taken together, we showed that $19-\mathrm{HB}$ attenuated the mobility of NSCLC cells.

The crucial step for the migration and invasion processes is passing throughout the extracellular matrix; the proteolytic activity is required for this process, including MMP2, MMP9, and MMP7, where the first two selectively degrade the major components of the ECM, while the third enzyme participates in metastasis [20]. To determine whether 19-HB inhibits migration and invasion through regulating MMPs, we examined the mRNA and protein levels of MMP2, MMP7, and MMP9 in 19-HB-treated NSCLC cells. As shown in Fig. 4, the expression levels of MMPs decreased at both mRNA and protein levels. These data suggested that 19-HB inhibited the mobility of NSCLC cells by also downregulating the expression of MMPs.

In addition, western blotting was used to measure the variations in epithelial-mesenchymal transition (EMT)related molecules to assess the influence of 19-HB on EMT. As shown in Fig. 5, compared with the untreated group, the epithelial marker ZO-1 increased $(P<0.01)$, and the mesenchymal markers $\mathrm{N}$-cadherin and Vimentin decreased. Since specific EMT-associated transcription factors (EMT-TFS) drive EMT process, we investigated whether the expression of EMT-TFS is regulated by $19-\mathrm{HB}$. The results showed that $19-\mathrm{HB}$ suppressed the expression level of Snail and Slug $(P<0.01$, Fig. 5a, b). A number of studies have shown that EMT is closely related to cancer metastasis. Therefore, our findings supported that the underlying mechanism of EMT suppression in 19-HB-treated NSCLC cells may be mediated by the inhibition of EMT-TFs.

\section{9-HB inhibited the activation of the Wnt/B-catenin signaling pathway in NSCLC cells}

Since Wnt/ $\beta$-catenin signaling pathway is important for regulating EMT process, we evaluated the expression levels of $\beta$-catenin, c-Myc, and Cyclin D1 by western blotting. All these proteins were key factors in Wnt/ $\beta$-catenin signaling pathway. We found that $19-\mathrm{HB}$ downregulated the protein expression of $\beta$-catenin $(P<0.05$ vs. control), c-Myc $(P<0.05$ vs. control), and Cyclin D1 $(P<0.01$ vs. control, Fig. 6a, b). PDK1/AKT/MDM2 and NFkB pathways were also tested in 19-HB treated cells, the results showed that PDK1/AKT/MDM2 pathway related proteins including phosphorylated-PDK1, AKT, the ratio of phosphorylated-MDM2 and total MDM2, appeared no significant difference, the similar results were observed in NFkB pathway (Additional file 1: Fig. S4). Hence, 19-HB mainly inhibited NSCLC cells by suppressing Wnt/ $\beta$ catenin signaling pathway.

\section{9-HB inhibited the growth of NSCLC in vivo}

Based on the in vitro data, we further investigated the in vivo antitumor ability of $19-\mathrm{HB}$ in NCI-H1299 xenograft Balb/c nude mice. After administration of 19-HB to the mice, both the tumor weights (Fig. 7b) and tumor volume (Fig. 7a) in the treated group significantly decreased compared with those in the control group $(P<0.01)$. The results illustrated that $19-\mathrm{HB}$ effectively inhibited the growth of NCI-H1299 tumor masses. Importantly, the nude mice had good tolerance to 19-HB with no obvious toxicity shown in biochemical analysis (Fig. 7c). In addition, IHC staining of Ki67 and immunofluorescence staining for TUNEL assay (Fig. 7d) showed reduced cell proliferation $(P<0.05)$ and increased apoptosis rate of the 19-HB group $(P<0.01)$. Our data suggested that $19-\mathrm{HB}$ reduced the viability of NSCLC cells and inhibited the tumors growth in vivo.

\section{Discussion}

Bufadienolides have shown significant drug potential for their antitumor activities, including suppressing cell proliferation, inducing apoptosis, inhibiting cancer angiogenesis, and regulating the immune response [21-26]. 
a
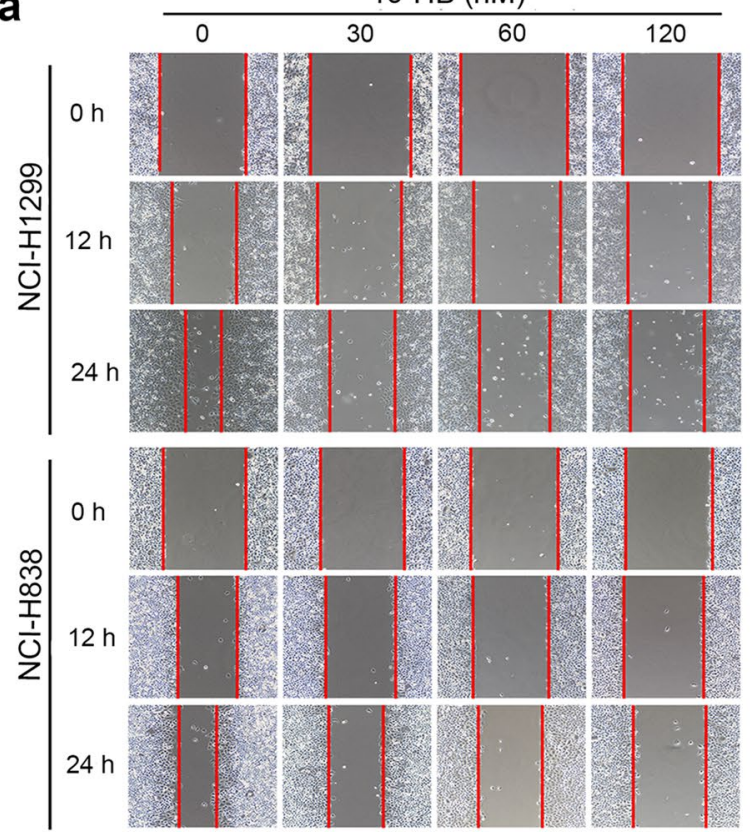
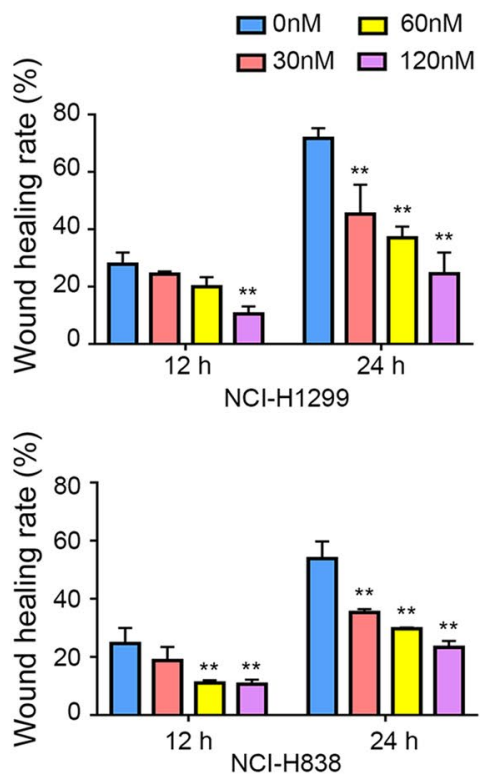

b
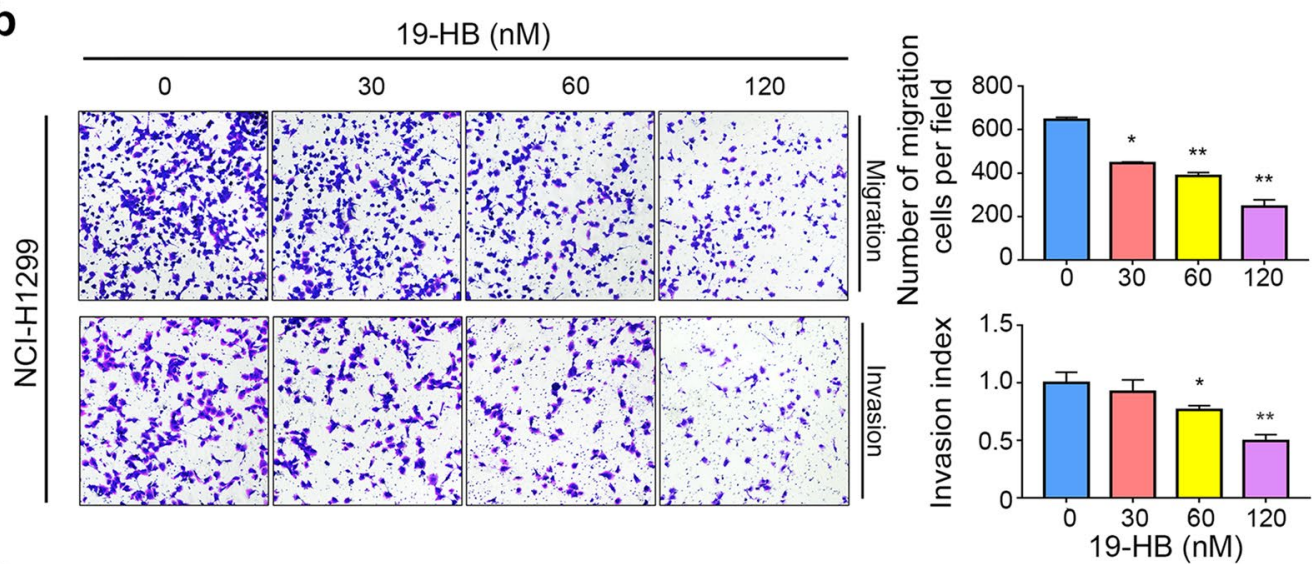

C
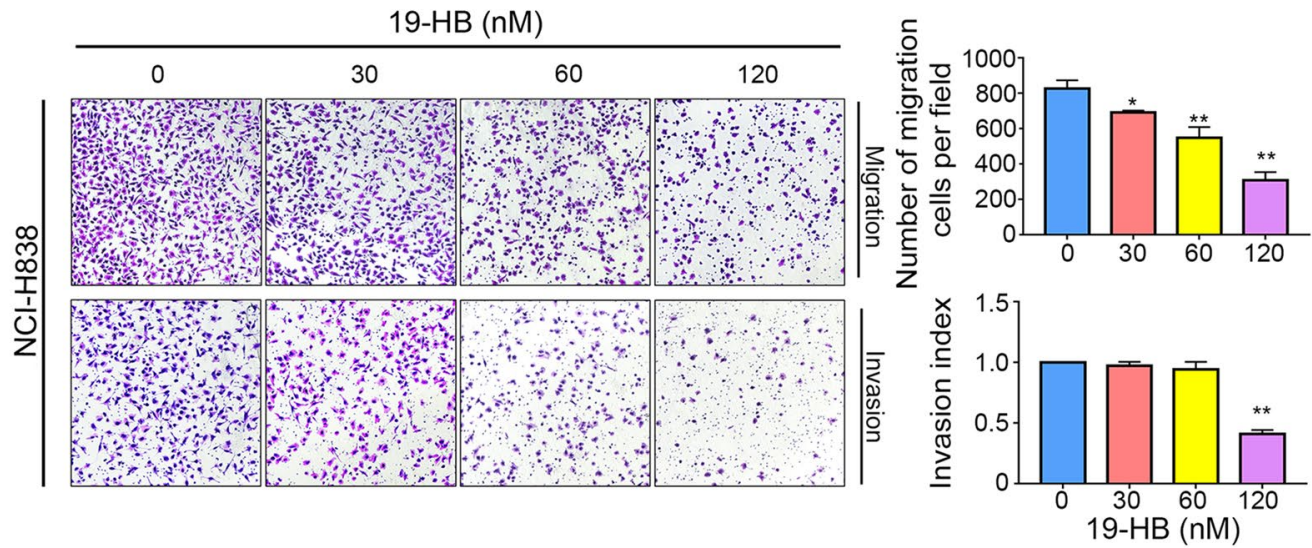

Fig. 3 19-HB inhibited NSCLC cells migration and invasion. NCl-H1299 and NCl-H838 cells were treated for $24 \mathrm{~h}$ with the indicated concentrations of 19-HB. a Wound healing rate quantitatively analyzed at the indicated times (12 and $24 \mathrm{~h}$ after injury). b, c Migration and invasion of NCl-H1299 (b) and $\mathrm{NCl}-\mathrm{H} 838$ (c) cells measured by transwell assay, and quantified by counting the migrating cells and calculating the invasion index in five randomly chosen high-power fields for each replicate $(n=3)\left({ }^{*} P<0.05\right.$ vs. control, ${ }^{* *} P<0.01$ vs. control) 
a

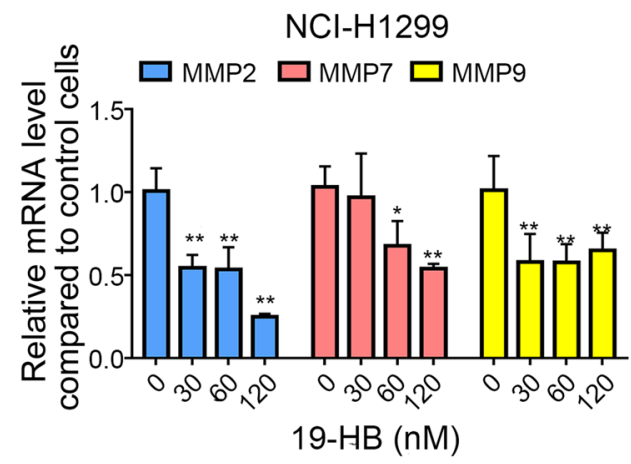

b

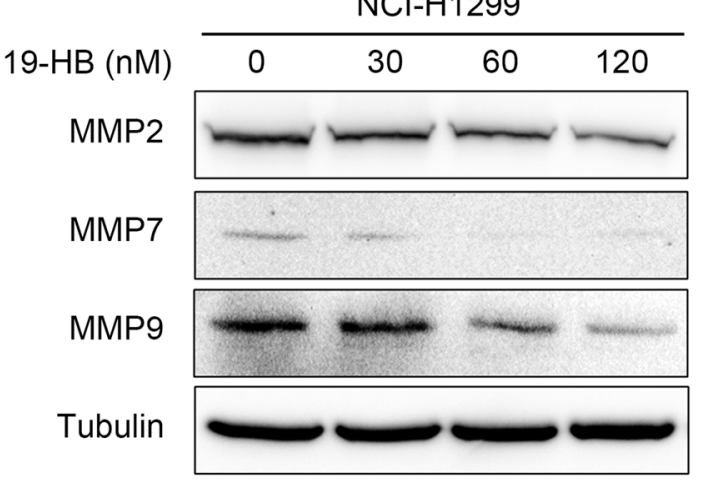

$\mathrm{NCl}-\mathrm{H} 838$

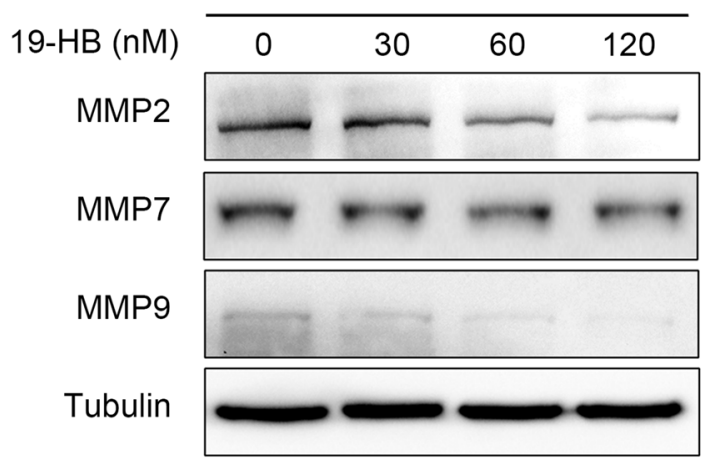

$\mathrm{NCl}-\mathrm{H} 838$
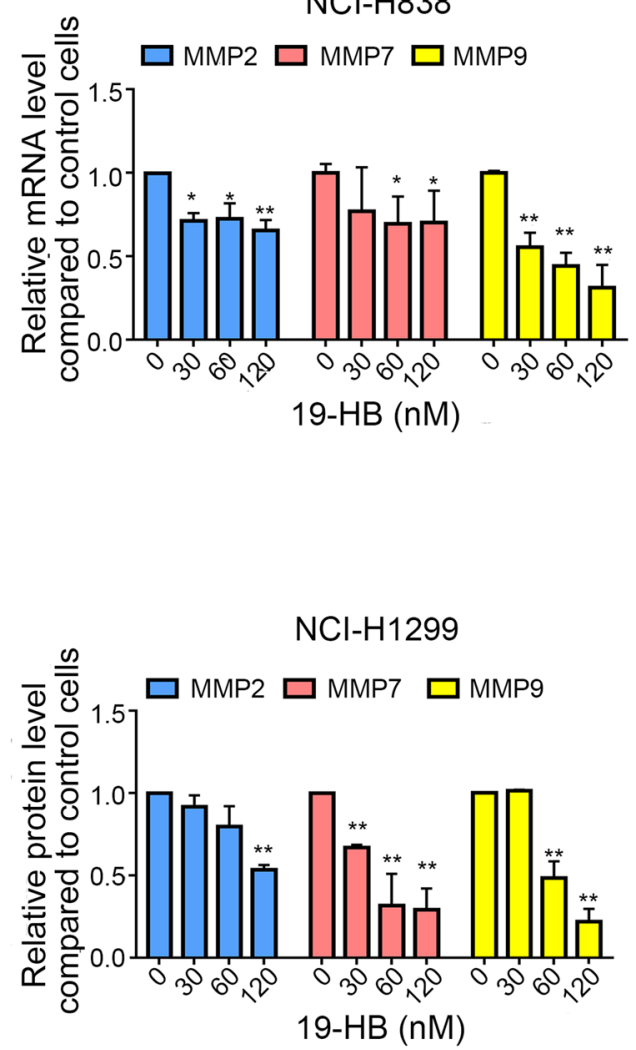

$\mathrm{NCl}-\mathrm{H} 838$

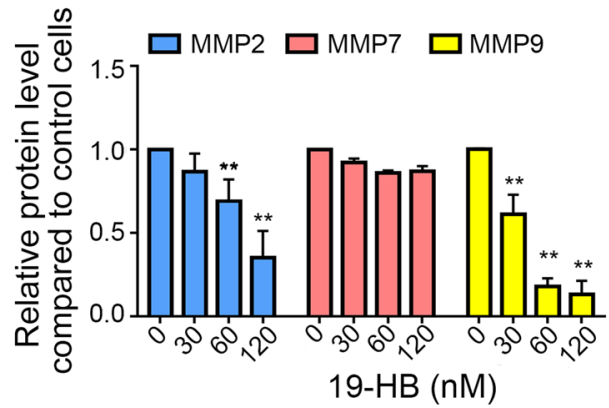

Fig. 4 19-HB inhibited expression levels of MMPs in NSCLC cells. a mRNA expression of MMPs in NSCLC cell lines. b Protein levels of MMPs in NSCLC indicated by western blotting. Tubulin was used as the loading control, and the quantitative data of the protein levels are shown $\left({ }^{*} P<0.05\right.$ vs. control, ${ }^{* *} P<0.01$ vs. control)

However, the molecular mechanism as to how these rare ingredients affect several biological functions both in vivo and in vitro remained elusive. 19-HB is a component of bufadienolides with significant antitumor activity, but few studies have focused on it or its biological activities. Thus, we evaluated the antitumor effects of $19-\mathrm{HB}$ in NCI-H1299 and NCI-H838 cell lines.
We reported that $19-\mathrm{HB}$ inhibited the proliferation of NSCLC cells. Subsequent experiments further confirmed that 19-HB showed extraordinary inhibitory effect on NSCLC migration and invasion in vitro along with a dose-dependent effect in promoting the apoptosis of NSCLC cells. Taking these results into account, we can hypothesize that $19-\mathrm{HB}$ plays its antitumor activity by 
a

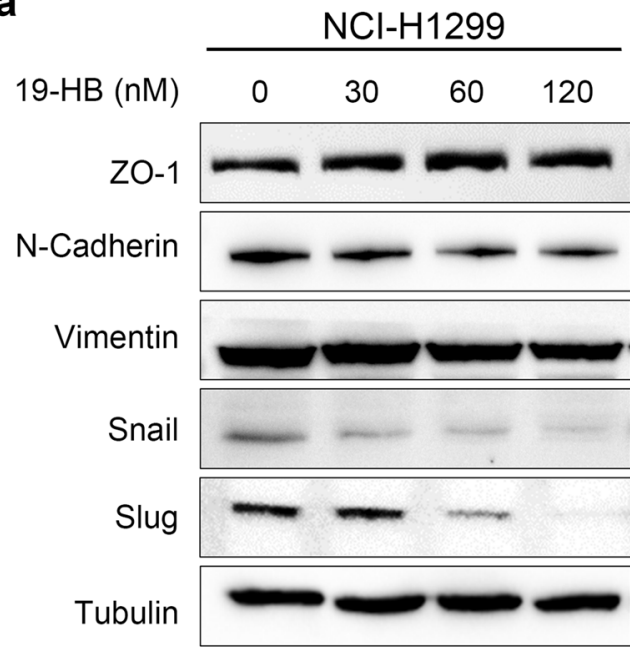

b

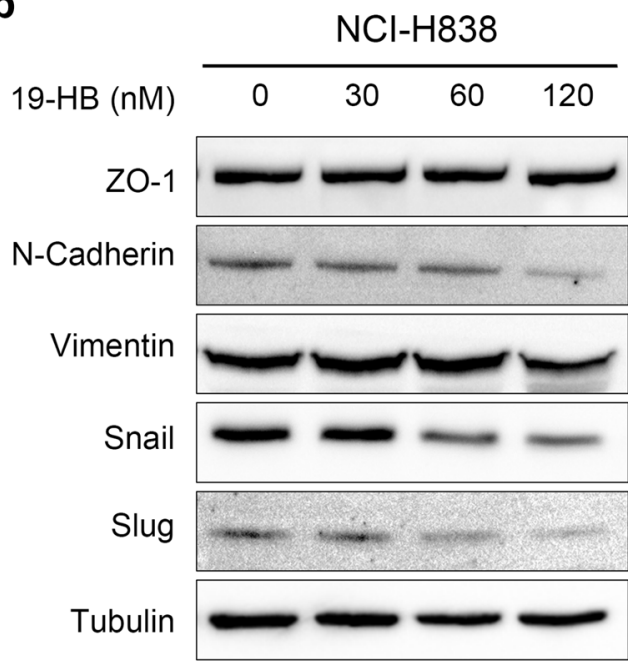

$\mathrm{NCl}-\mathrm{H} 1299$

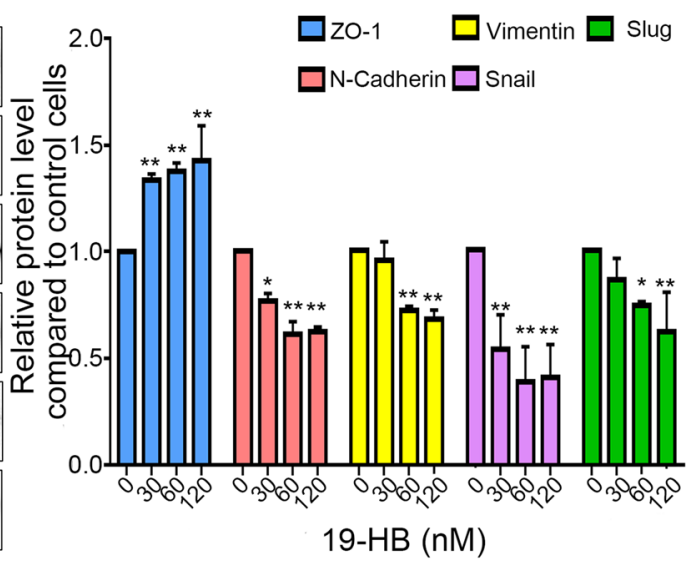

$19-\mathrm{HB}(\mathrm{nM})$

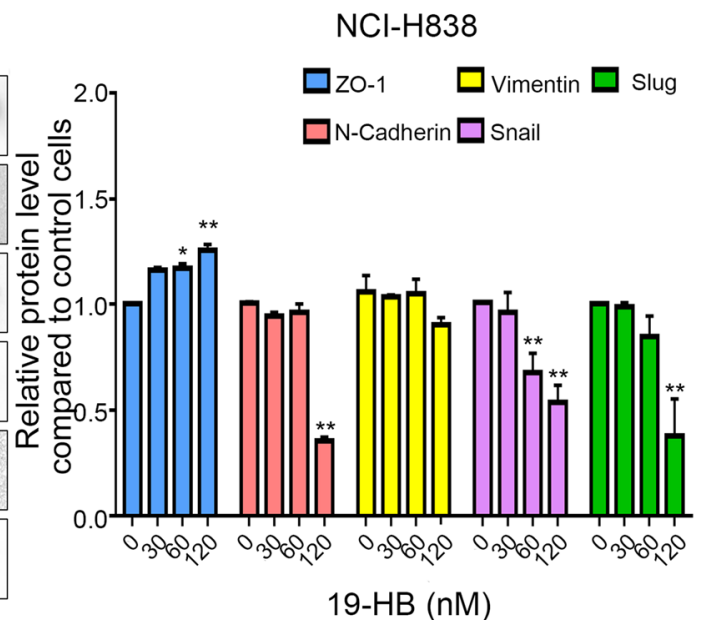

Fig. 5 19-HB inhibited expression levels of EMT-associated factors in NSCLC cells. a, b Protein levels of EMT and relative protein expression in $\mathrm{NCl}-\mathrm{H} 1299$ (a) and NCl-H838 (b) cells ( ${ }^{*} P<0.05$ vs. control, ${ }^{* *} P<0.01$ vs. control)

suppressing the cell proliferation, migration, and invasion of NSCLC cells.

Apoptosis is an important biological process that maintains homeostasis in organisms and cells. Apoptosis is a programmed cell death process; it shows chromatin condensation and nuclear fragmentation as the main characteristics, and it is accompanied by morphological changes and reduction in cellular volume [19]. Antitumor drugs mainly act by inhibiting cell proliferation and promoting apoptosis to kill tumor cells [27]. Both the intrinsic pathway and the extrinsic pathway mediates the cell apoptosis [28]. In the intrinsic apoptotic pathway, after the death signal is received, disruption of the mitochondrial membrane occurs subsequently, resulting in the release of cytochrome $\mathrm{c}$ from the mitochondria matrix into the cytosol and activation of caspase-3. Caspase- 3 is one of the executor caspases for the apoptosis pathways. The activation of caspase- 3 cleaves its substrate, PARP, into two fragments, thus triggering apoptosis through DNA fragmentation [29]. In addition, Bax-a member of the Bcl-2 family-also participates in the intrinsic apoptosis pathway [30]. Bax is generally present in the cytoplasm; after receiving the apoptotic signal, Bax relocates to the mitochondrial 

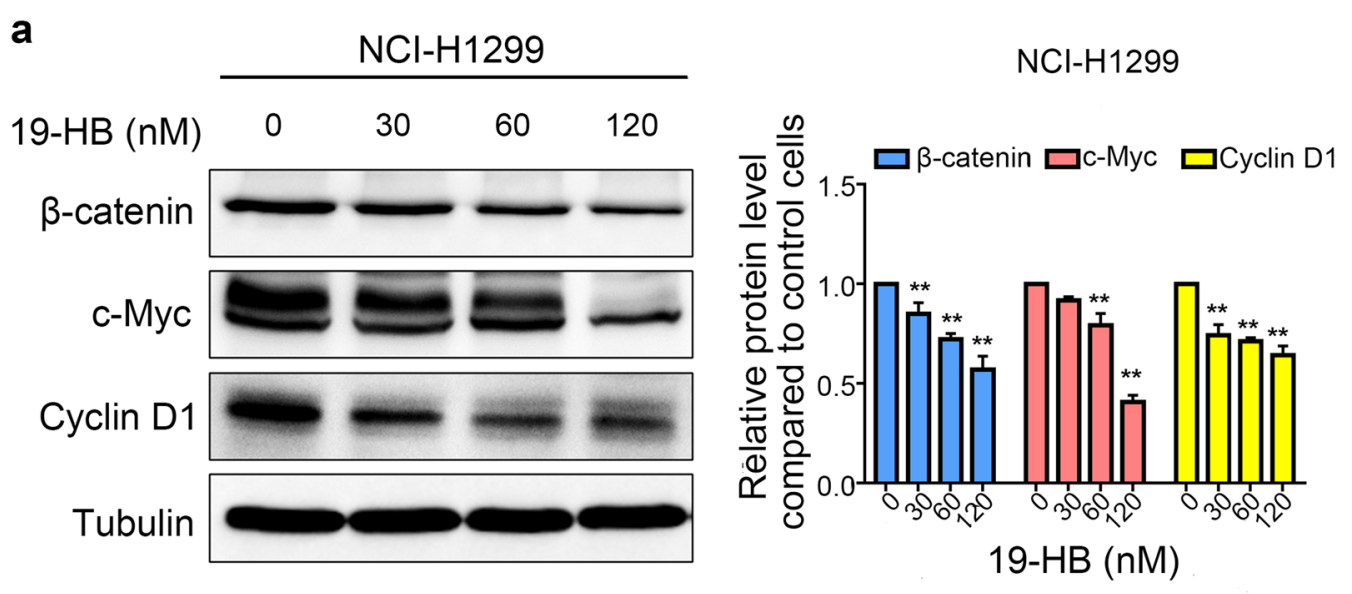

b

$\mathrm{NCl}-\mathrm{H} 838$

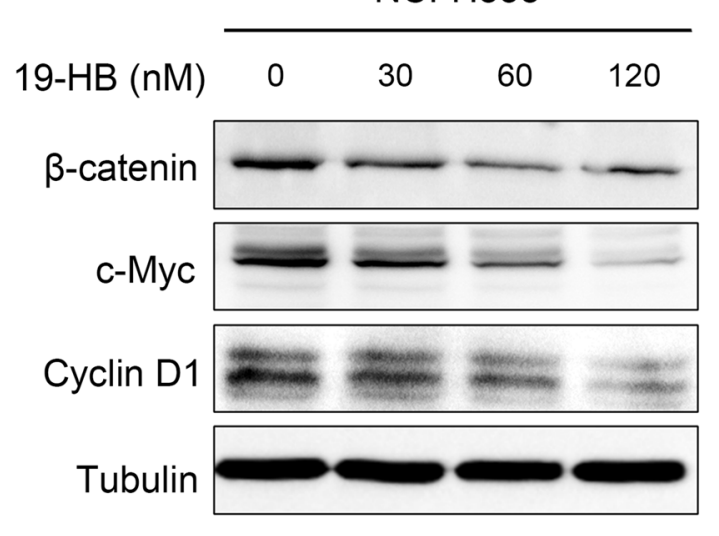

$\mathrm{NCl}-\mathrm{H} 838$

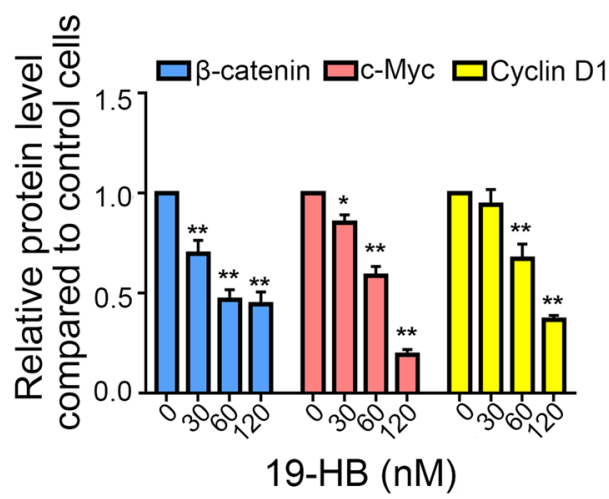

Fig. 6 19-HB inhibited the Wnt/ $\beta$-catenin signaling pathway. a, b Western blotting showed that 19-HB downregulated $\beta$-catenin, c-Myc, and Cyclin D1 in NCl-H1299 (a) and NCI-H838 (b) cells $\left({ }^{*} P<0.05\right.$ vs. control, ${ }^{* *} P<0.01$ vs. control)

surface and forms a transmitochondrial membrane hole on the mitochondrial surface. Subsequently, the mitochondrial membrane potential decreases and membrane permeability increases, thus releasing apoptotic factors into the cytosol; this process can be measured by the ratio of $\mathrm{Bcl}-2$ and $\mathrm{Bax}$. In this study, we examined the mitochondrial membrane potential and the expression signature of apoptosis-related proteins in 19-HBtreated NSCLC cells. We also observed the necroptosis in 19-HB-treated cells, necroptotic-related proteins, such as RIP, MLKL, only showed a slightly changed, but did not achieve statistically significant. Our data indicated that $19-\mathrm{HB}$ reduced the mitochondrial transmembrane potential, activated cleaved caspase-3, and cleaved PARP, ultimately leading to apoptosis.

Metastasis of malignant tumors is the most important cause of patient death and is the key problem that needs to be overcome during tumor treatment. Previous studies showed that the expression levels of MMP2, MMP7 and MMP9 is positively correlated with the plasticity of tumor cells, such as invasion depth, metastasis distance, and vascular permeability [31]. Therefore, we further explored the changes in EMT-related proteins in 19-HB-treated NSCLC cells; the results showed that

(See figure on next page.)

Fig. 7 19-HB inhibited NSCLC growth in vivo. Xenograft Balb/c nude mice model was established with NCl-H1299 cells, and the mice were euthanized after completing the treatment. a Tumor volumes of tumor-bearing Bulb/c mice measured on the indicated days. $\mathbf{b}$ Tumor size and tumor weights measured. c Serum biochemical indexes to reflect the hepatorenal toxicity of 19-HB. d IHC staining for Ki67 and immunofluorescence staining for TUNEL assay performed in tumor mass, and the positive rate of Ki67 and TUNEL determined on IHC staining afterward ( ${ }^{*} P<0.05$ vs. control, ${ }^{*} P<0.01$ vs. control) 

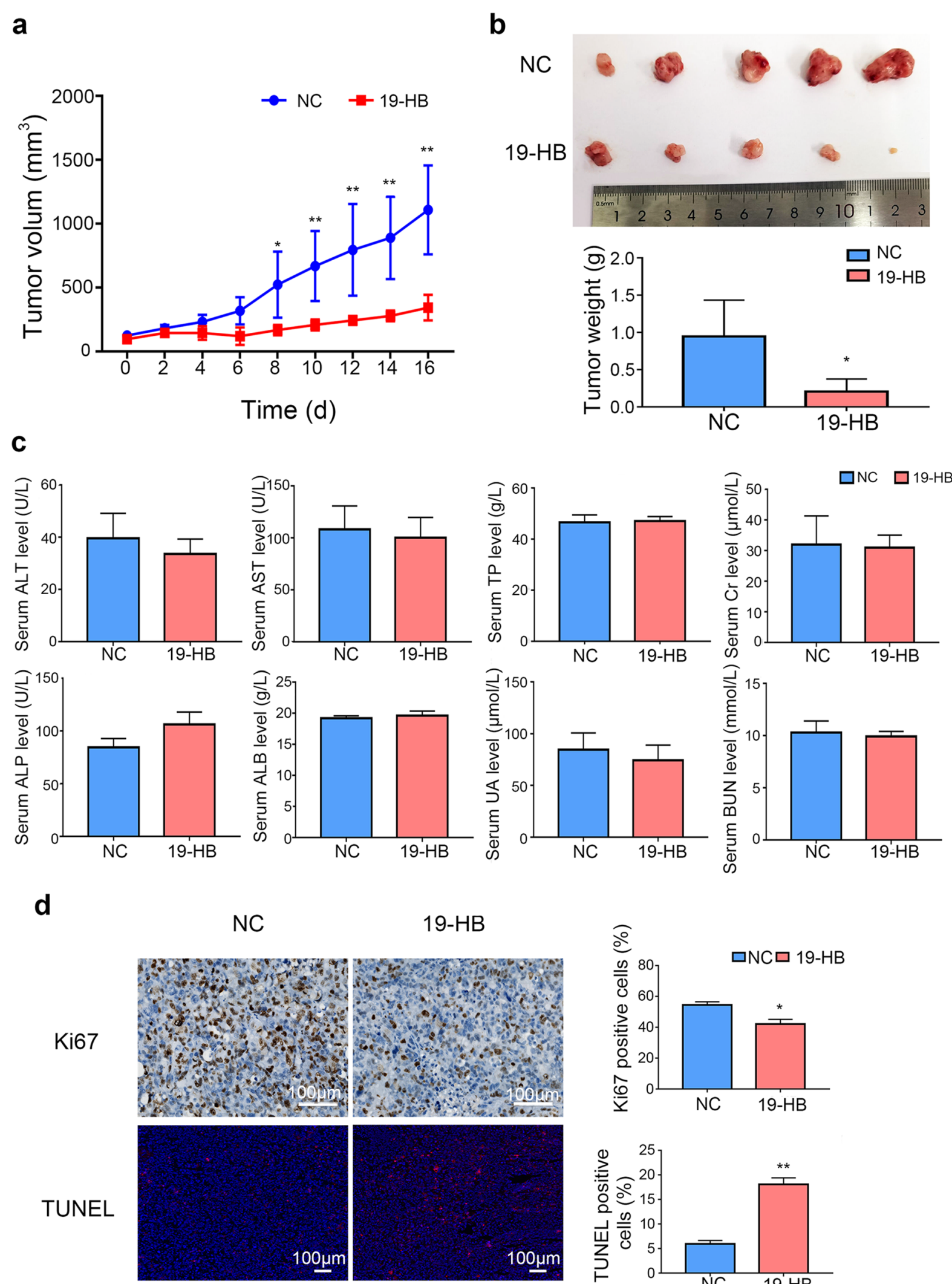

Fig. 7 (See legend on previous page.)
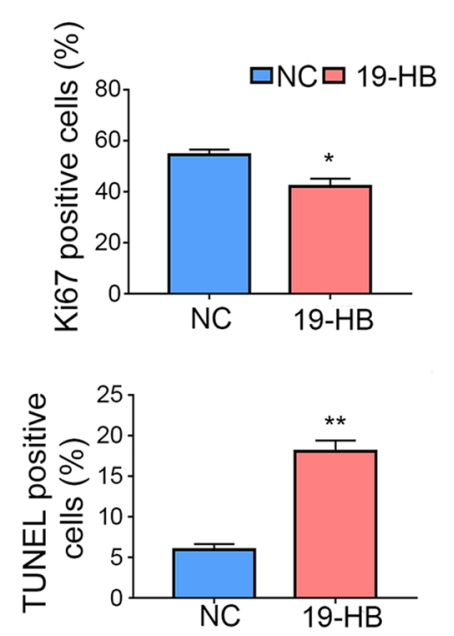
19-HB decreased the expression of the mesenchymal markers $\mathrm{N}$-cadherin and Vimentin, while the epithelial marker ZO-1 was increased. Similarly, 19-HB suppressed the function of the transcription factors of EMT. EMT is one the most important biological behaviors in cancer, during EMT process, tumor cells acquire mesenchymal cell properties and lose their epithelial characteristics, which subsequently leads to high metastatic potential [32]. Therefore, 19-HB may inhibit tumor cell migration and invasion by regulating EMT signals. Moreover, we screened the leading signaling pathways that regulate EMT, such as the TGF- $\beta$, Notch, Wnt/ $\beta$-catenin, PI3K/AKT, and ERK pathways [33], by western blotting; the results showed that $19-\mathrm{HB}$ negatively regulated the expression of $\beta$-catenin, Cyclin D1, and c-Myc, the known targets of the $\mathrm{Wnt} / \beta$-catenin signaling pathway [34-37]. The aberrant Wnt/ $\beta$-catenin signaling pathway is known to play crucial roles in tumorigenesis and remains a hot target for anti-cancer drug development [38]. Therefore, our findings suggested that the antitumor effects of 19-HB in NSCLC cells can be mediated through suppression of Wnt/ $\beta$-catenin signaling pathway.

The application of actionable TCM compounds in NSCLC opens the way for clinical treatment. We identified a monomer from the skin of toads, 19-HB, with good antitumor activity; we also clarified its primary mechanism of attenuating progression of NSCLC. However, some improvements are still needed to alleviate the untoward effects and improve the efficacy of first-line therapies for lung cancer; in that context, we foresee that the explorations of combination therapies with 19-HB could answer this question.

\section{Conclusions}

Our study indicated that 19-HB inhibited proliferation of NSCLC cells, promoted cell apoptosis, and inhibited cell mobility. These effects were achieved by suppressing the expression of EMT-related markers and inhibiting the activity of the Wnt/ $\beta$-catenin signaling pathway. Thus, $19-\mathrm{HB}$ may be a potential antitumor agent for NSCLC.

\footnotetext{
Abbreviations

19-HB: 19-Hydroxybufalin; ALB: Albumin; ALP: Alkaline phosphatase; ALT: Alanine aminotransferase; AST: Aspartate transaminase; Bax: Bcl-associated $x$ protein; BCA: Bicinchoninic acid; BCl-2: B cell lymphoma/leukemia-2; BSA: Bovine serum albumin; BUN: Blood urea nitrogen; Caspase: Cysteine-containing aspartate specific protease; CR: Creatinine; ECM: Extracellular matrix; EMT: Epithelial-to-mesenchymal transition; IHC: Immunohistochemistry; MMP: Matrix metalloproteinase; NSCLC: Non-small cell lung cancer; OD: Optical density; RT-qPCR: Real-time quantitative polymerase chain reaction; TP: Total protein; TUNEL: Terminal deoxynucleotidyl mediated dUTP nick end transferase labeling; UA: Uric acid.
}

\section{Supplementary Information}

The online version contains supplementary material available at https://doi. org/10.1186/s40164-021-00243-0.

Additional file 1: Fig. S1. 19-HB inhibited NSCLC cell growth. Fig. S2. 19-HB inhibited cell proliferation in certain cancer cell lines. Fig. S3. 19-HB had little effects of necroptosis in NSCLC cells. Fig. S4. 19-HB inhibited tumor cell growth not through the PDK1/AKT/MDM2 and NFKB signaling pathways.

\section{Acknowledgements}

The authors thank Dr. Guoan Chen for his helpful discussion, Mr. Fuhao Wang for his technical help, Ms. Xin Huang, Tianzi Wei, and Xinyu Ye for their editing.

\section{Authors' contributions}

WY, MGX, YLu, YLiu, and JZ contributed to the conception and design of this study; WY, XZ, MGX, YLu, YLiu and JZ wrote and revised the manuscript; experiments were carried out by WY, XZ, YHL, MC, WZ; WY, XZ, AND LX participated in data analysis and interpretation. All the authors read and approved the final manuscript.

\section{Funding}

The study was supported by NSFC 81773146, 81972766, 81972420, 81802949; Shenzhen Science \& Technology Innovation Commission, Key project, JCYJ20170412152943794, JCYJ20170412154619484; Guizhou Provincial Science and Technology support program (QKHZC-2020-4Y156); and Innovation Talent Team of Zunyi (ZSKRC [2019] 1).

\section{Availability of data and materials}

The data used during the current study are available from the corresponding author on reasonable request.

\section{Declarations}

Ethics approval and consent to participate

The use of the animals for research purposes was approved by the Experimental Animal Welfare Ethics Committee of Southern University of Science and Technology (Approval No. SUSTC-JY2019163).

\section{Consent for publication}

Not applicable.

\section{Competing interests}

The authors declare that they have no competing interests.

\section{Author details}

${ }^{1}$ Guizhou Provincial College-Based Key Lab for Tumor Prevention and Treatment With Distinctive Medicines, Zunyi Medical University, Zunyi 563000,

China. ${ }^{2}$ School of Medicine, Southern University of Science and Technology, Shenzhen 518055, Guangdong, China. ${ }^{3}$ Guangdong Provincial Key Laboratory of Cell Microenvironment and Disease Research, Shenzhen 518055, Guangdong, China.

Received: 15 April 2021 Accepted: 21 October 2021

Published online: 25 October 2021

References

1. Siegel RL, Miller KD, Jemal A. Cancer statistics, 2020. CA Cancer J Clin. 2020;70(1):7-30.

2. Molina JR, Yang P, Cassivi SD, Schild SE, Adjei AA. Non-small cell lung cancer: epidemiology, risk factors, treatment, and survivorship. Mayo Clin Proc. 2008;83(5):584-94 
3. Qiu Z, Chen Z, Zhang C, Zhong W. Achievements and futures of immune checkpoint inhibitors in non-small cell lung cancer. Exp Hematol Oncol. 2019;8:19.

4. Chen R, Manochakian R, James L, Azzouqa AG, Shi H, Zhang Y, Zhao Y, Zhou K, Lou Y. Emerging therapeutic agents for advanced non-small cell lung cancer. J Hematol Oncol. 2020;13:58.

5. Verma V, Sharma G, Singh A. Immunotherapy in extensive small cell lung cancer. Exp Hematol Oncol. 2019;8:5.

6. Niu M, Yi M, Li N, Luo S, Wu K. Predictive biomarkers of anti-PD-1/PD-L1 therapy in NSCLC. Exp Hematol Oncol. 2021;10:18.

7. Herbst RS, Morgensztern D, Boshoff $C$. The biology and management of non-small cell lung cancer. Nature. 2018;553(7689):446-54.

8. Zhang $\mathrm{H}$, Kong Q, Wang J, Jiang Y, Hua H. Complex roles of CAMP-PKACREB signaling in cancer. Exp Hematol Oncol. 2020;9:32.

9. Yi M, Li T, Qin S, Yu S, Chu Q, Li A, Wu K. Identifying tumorigenesis and prognosis-related genes of lung adenocarcinoma: based on weighted gene coexpression network analysis. Biomed Res Int. 2020;2020:4169691.

10. Rodriguez C, Rollins-Smith L, Ibanez R, Durant-Archibold AA, Gutierrez $M$. Toxins and pharmacologically active compounds from species of the family Bufonidae (Amphibia, Anura). J Ethnopharmacol. 2017;198:235-54

11. Chen KK, Kovarikova A. Pharmacology and toxicology of toad venom. J Pharm Sci. 1967:56(12):1535-41.

12. Lan $Y L$, Lou JC, Jiang XW, Wang $X$, Xing JS, Li S, Zhang B. A research update on the anticancer effects of bufalin and its derivatives. Oncol Lett. 2019;17(4):3635-40

13. Qi F, Li A, Inagaki Y, Kokudo N, Tamura S, Nakata M, Tang W. Antitumor activity of extracts and compounds from the skin of the toad Bufo bufo gargarizans Cantor. Int Immunopharmacol. 2011;11(3):342-9.

14. Qi J, Zulfiker AHM, Li C, Good D, Wei MQ. The development of toad toxins as potential therapeutic agents. Toxins (Basel). 2018;10(8):336.

15. Meng Z, Yang P, Shen Y, Bei W, Zhang Y, Ge Y, Newman RA, Cohen L, Liu L, Thornton B, et al. Pilot study of huachansu in patients with hepatocellular carcinoma, nonsmall-cell lung cancer, or pancreatic cancer. Cancer. 2009;115(22):5309-18

16. Zhiyong D. Cinobufacini injection for moderate and advanced primary liver cancer: a systematic review and meta-analysis. J Chin Pharm Sci. 2019;28(4):264-75.

17. Wang Z, Qi F, Cui Y, Zhao L, Sun X, Tang W, Cai P. An update on Chinese herbal medicines as adjuvant treatment of anticancer therapeutics. Biosci Trends. 2018;12(3):220-39.

18. Hu Y, Yu Z, Yang ZJ, Zhu G, Fong W. Comprehensive chemical analysis of Venenum Bufonis by using liquid chromatography/electrospray ionization tandem mass spectrometry. J Pharm Biomed Anal. 2011;56(2):210-20.

19. Wong RS. Apoptosis in cancer: from pathogenesis to treatment. J Exp Clin Cancer Res. 2011:30:87.

20. Kessenbrock K, Plaks V, Werb Z. Matrix metalloproteinases: regulators of the tumor microenvironment. Cell. 2010;141(1):52-67.

21. Xie CM, Chan WY, Yu S, Zhao J, Cheng CH. Bufalin induces autophagymediated cell death in human colon cancer cells through reactive oxygen species generation and JNK activation. Free Radic Biol Med. 2011;51(7):1365-75

22. Niu T, Zhao L, Lin X, Cai Y, Chen S, Wang M, Zhou L, Ding H, Yu X, Qin G. Cinobufagin, a bufadienolide from traditional Chinese medicine Bufo bufo gargarizans CANTOR, inhibits PC3 cell growth in vitro and in vivo. J Trad Chin Med Sci. 2019;6(2):175-83.

23. Huang WW, Yang JS, Pai SJ, Wu PP, Chang SJ, Chueh FS, Fan MJ, Chiou $\mathrm{SM}$, Kuo HM, Yeh CC, et al. Bufalin induces G0/G1 phase arrest through inhibiting the levels of cyclin D, cyclin E, CDK2 and CDK4, and triggers apoptosis via mitochondrial signaling pathway in T24 human bladder cancer cells. Mutat Res. 2012;732(1-2):26-33.

24. Lan YL, Wang X, Lou JC, Xing JS, Yu ZL, Wang H, Zou S, Ma X, Zhang B. Bufalin inhibits glioblastoma growth by promoting proteasomal degradation of the $\mathrm{Na}(+) / \mathrm{K}(+)$-ATPase alpha1 subunit. Biomed Pharmacother. 2018;103:204-15.

25. Feng Y, Chen Y, Meng Y, Cao Q, Liu Q, Ling C, Wang C. Bufalin suppresses migration and invasion of hepatocellular carcinoma cells elicited by poly (I:C) therapy. Oncoimmunology. 2018;7(5):e1426434.

26. Wang $H$, Zhang C, Ning Z, Xu L, Zhu X, Meng Z. Bufalin enhances anti-angiogenic effect of sorafenib via AKTNEGF signaling. Int J Oncol. 2016:48(3):1229-41.

27. An W, Lai H, Zhang Y, Liu M, Lin X, Cao S. Apoptotic pathway as the therapeutic target for anticancer traditional chinese medicines. Front Pharmacol. 2019;10:758

28. Carneiro BA, El-Deiry WS. Targeting apoptosis in cancer therapy. Nat Rev Clin Oncol. 2020;17(7):395-417.

29. Soldani C, Scovassi Al. Poly(ADP-ribose) polymerase-1 cleavage during apoptosis: an update. Apoptosis. 2002;7(4):321-8.

30. Ashkenazi A, Fairbrother WJ, Leverson JD, Souers AJ. From basic apoptosis discoveries to advanced selective BCL-2 family inhibitors. Nat Rev Drug Discov. 2017:16(4):273-84

31. Quintero-Fabian S, Arreola R, Becerril-Villanueva E, Torres-Romero JC, Arana-Argaez V, Lara-Riegos J, Ramirez-Camacho MA, Alvarez-Sanchez ME. Role of matrix metalloproteinases in angiogenesis and cancer. Front Oncol. 2019:9:1370.

32. Lamouille $S, X u$ J, Derynck R. Molecular mechanisms of epithelial-mesenchymal transition. Nat Rev Mol Cell Biol. 2014;15(3):178-96.

33. Gonzalez DM, Medici D. Signaling mechanisms of the epithelial-mesenchymal transition. Sci Signal. 2014;7(344):re8

34. Hwang SY, Deng X, Byun S, Lee C, Lee SJ, Suh H, Zhang J, Kang Q, Zhang $T$, Westover KD, et al. Direct targeting of beta-catenin by a small molecule stimulates proteasomal degradation and suppresses oncogenic Wnt/ beta-catenin signaling. Cell Rep. 2016;16(1):28-36.

35. Rennoll S, Yochum G. Regulation of MYC gene expression by aberrant Wnt/beta-catenin signaling in colorectal cancer. World J Biol Chem. 2015:6(4):290-300

36. Koh CM, Sabo A, Guccione E. Targeting MYC in cancer therapy: RNA processing offers new opportunities. BioEssays. 2016;38(3):266-75.

37. Musgrove EA, Caldon CE, Barraclough J, Stone A, Sutherland RL. Cyclin D as a therapeutic target in cancer. Nat Rev Cancer. 2011;11(8):558-72.

38. Zhang $Y$, Wang $X$. Targeting the Wnt/beta-catenin signaling pathway in cancer. J Hematol Oncol. 2020;13(1):165.

\section{Publisher's Note}

Springer Nature remains neutral with regard to jurisdictional claims in published maps and institutional affiliations.

Ready to submit your research? Choose BMC and benefit from

- fast, convenient online submission

- thorough peer review by experienced researchers in your field

- rapid publication on acceptance

- support for research data, including large and complex data types

- gold Open Access which fosters wider collaboration and increased citations

- maximum visibility for your research: over 100M website views per year

At $\mathrm{BMC}$, research is always in progress.

Learn more biomedcentral.com/submissions 